\title{
MANAGEMENT OF THE INFECTED HIP ARTHROPLASTY BY TWO-STAGE REIMPLANTATION
}

\author{
Karel Karpaš, Pavel Šponer \\ Charles University in Prague, Faculty of Medicine in Hradec Králové: Department of Orthopaedic Surgery \\ Summary: The aim of this study is to present our experience with two-stage reimplantation in the management of the in- \\ fected hip arthroplasty. Between January 1993 and December 2001 the replacement of the total hip arthroplasty in two \\ stages was performed in 18 patients. There were 7 male and 11 female patients and the average age was 62 years. The mean \\ follow-up after revision was 3.5 years. The mean postoperative Harris Hip Score averaged 78 (50-96) points. None of 18 \\ patients had a recurrence of the infection. Two-stage reconstruction of the infected hip is preferred to one-stage exchange \\ arthroplasty at our department because of higher rate of eradication of the infection.
}

Key words: Total hip arthroplasty; Infection; Two-stage exchange arthroplasty

\section{Introduction}

Possible option for the operative management of an infected hip arthroplasty includes débridement with retention of the prosthesis, immediate one-stage exchange arthroplasty and resection arthroplasty, either as a definitive procedure or as the first of a two-stage reconstructive procedure $(4,6,7,13)$. The choice of a particular treatment is affected by a number of factors (17).

The purpose of this study is to present our experience with two-stage exchange arthroplasty in patients who had an infected hip prosthesis.

\section{Material and Methods}

Between January 1993 and December 2001 we performed resection arthroplasty of the hip in 51 patients who had infected hip prosthesis.

Replacement of the total hip prosthesis in two stages had been carried out in 18 of these 51 patients during follow-up in 2002. There were 7 male and 11 female patients in the study and the average age was 62 years (range 46 years to 75 years). The series included various infected prostheses: 9 cemented total hip prostheses, 1 cemented tumourous total hip prosthesis, 2 cemented hemiarthroplasties and 6 hybrid total hip prostheses. The primary diagnoses were primary osteoarthritis in 10 patients, postdysplastic osteoarthritis and femoral neck fracture in 3 patients each and posttraumatic osteoarthritis in 2 patients. The patients had the following systemic diseases: diabetes mellitus in two, thyreopathy and ochronosis in one patient each.

Early postoperative infection, occured within one month after the operation, was present in 4 cases. Late postoperative infection, occured more than a month after the operation, was present in 14 cases. A single microorganism was isolated in specimens from 9 hips and more than one microorganism in specimens from 2 hips. There were no microorganisms isolated from 7 specimens because of preoperative antibiotic therapy given by the referring surgeon.

The interval between the first and second stage of a twostage exchange arthroplasty has varied widely. In our first group of 9 patients, who were treated at our department till January 1999, a total hip reimplantation had been carried out after an average of 10 months. Nowadays we prefer the interval from 3 to 4 months. The following prostheses were used for the revision: acetabular components - 7 cemented Ultima (Johnson and Johnson), 3 cemented Poldi (Beznoska), 1 cemented Exeter (Howmedica), 2 cementless Plasmacup (Aesculap), 2 cementless LOR (Allopro), 1 cementless CLS (Protek), 1 cementless ABG (Howmedica), 1 cementless Zweymuller (Allopro), femoral components 6 cemented standard Poldi (Beznoska), 5 cemented extreme Poldi (Beznoska), 3 cementless revision stem SL (Protek), 2 cementeless revision stem Aesculap (Aesculap), 1 cementless ABG (Howmedica) and 1 cementless Zweymuller (Allopro). The bone autografts were used in 8 patients for the acetabulum. Antibiotics were administered postoperatively to all patients for 6 weeks. 
The mean follow-up after reconstruction was 3.5 years. At follow-up the range of movement of the hip was examined and a questionnaire completed. The Harris Hip Score for the individual patients was used based on these data.

\section{Results}

Mean postoperative Harris Hip Score averaged 78 (50-96) points in our 18 patients. Fifteen patients suffered from no or slight pain, the other 3 had moderate pain. Walking distance was unlimited in 9 patients and limited in 9 cases too. The mean range of flexion in the hip was 89 degrees. The mean shortening of the involved extremity was $1.5 \mathrm{~cm}$. The Trendelenburg sign was negative in 6 patients.

None of 18 patients had a recurrence of the infection at an average follow-up of 3.5 years. Complications of the treatment included hip dislocation in 2 cases and aseptic loosening of the cemented total hip arthroplasty in 3 cases.

\section{Discussion}

Operative treatment of an infected hip arthroplasty includes débridement with retention of the prosthesis, immediate one-stage exchange arthroplasty, resection arthroplasty as a permanent procedure and two-stage exchange arthroplasty. There are these following factors important for choice of a particular treatment: the infecting microorganism and its ability to manufacture glycocalyx, its sensitivity to antibiotics, the duration of the infection, the condition of the patient, the fixation of the implants, the presence of the bone defects and the surgeon's philosophy $(2,7,18)$.

It is generally accepted that the débridement with retention of the prosthesis can be successful only in patients treated for early postoperative and late hematogenous infection of well fixed cemented total hip arthroplasty (5).

The resection arthroplasty of the hip is highly effective in infection controlling and reducing pain, but it is associated with considerable loss of function. This procedure is usually unacceptable as a definitive solution for relatively young and active patients $(1,15,16)$. However, not even the resection arthroplasty is quite without a risk of the recurrence of the infection. There was reported a 18 per cent rate of the recurrence after the removal of the infected hip arthroplasty $(3,17)$.

Reimplantation after débridement and removal of a prosthesis can be performed during the same procedure (one stage) or later (two stages). The use of these techniques varies among different centers $(8,10,12,14)$. At our department two-stage reconstruction is preferred to one-stage exchange arthroplasty because of higher rate of eradication of the infection. We observed no recurrence after two-stage procedure in 18 patients and 8 recurrences after one-stage procedure in 11 patients $(9)$.

The principles of a two-stage exchange arthroplasty include removal of the implants and all cement with débride- ment, postoperative administration of antibiotics and eventual implantation of a new total hip prosthesis. The interval between the first and second stages has varied widely and nowadays the interval from 3 to 4 months is preferred at our department. We proceed with reimplantation if clinical appearance and erythrocyte sedimentation rate with C-reactive protein level are indicative of resolution of the infection. Our approach minimizes the risk of the infection recurrence (9). The use of the cement spacer was reported recently to provide the patients with comfort and the spacer also reduces the dead space and soft tissue shortening thereby facilitating easier reimplantation $(8,11)$.

\section{Conclusions}

Two-stage reconstruction of the infected hip is preferred at our institution to one-stage exchange arthroplasty because of higher rate of eradication of the infection. Nowadays the interval between the first and second stage ranges from 3 to 4 months and the prostheses inserted without bone cement are used. Although methods for the diagnosis and treatment of the infected hip prosthesis were improved, the importance of the prevention cannot be overemphasized.

\section{References}

1. Bourne RB, Hunter GA, Rorabeck CH, Macnab JJ. A six year follow-up infected total hip arthroplasty managed by Girdlestone's arthroplasty. J Bone Jt Surg 1984:66-B:340-3.

2. Buchholz HW, Elson RA, Engelbrecht E, Lodenkamper H, Rottger J, Siegel A. Management of deep infection of total hip arthroplasty. J Bone Jt Surg 1981: 63-B:342-53.

3. Canner GC, Steiberg ME, Heppenstall, RB, Balderston R. The infected hip after total hip arthroplasty. J Bone Jt Surg 1984:66-A:1393-9.

4. Coventry MB. Treatment of infections occuring in total hip surgery. Orthop Clin North Am 1975:6:991-1003.

5. Crockarell JR, Hansen AD, Osmon DR, Morrey BF. Treatment of infection with débridement and retention of the components following hip arthroplasty. J Bone Jt Surg 1998:80-A:1306-13

6. Fitzgerald RH. Infected total hip arthroplasty: diagnosis and treatment. J Amer Acad Orthop Surg 1995:3.

7. Garvin KL, Hansen $\mathrm{AD}$. Infection after total hip arthroplasty. Past, present, and future. J Bone Jt Surg 1995,77-A:1576-88.

8. Ivarsson I, Wahlstrom O, Dierf K, Jacobson SA. Revision of infected hip replacement. Two-stage procedure with a temporary gentamicin spacer. Acta Orthop Scand 1994:65:7-8.

9. Karpaš K, Šponer P. The delayed-exchange protocol in the treatment of the periprosthetic hip infection. In: Duhaime DL, ed. Abstract book - SICOT/SIROT XXII World Congress 2002. Montreal: Sorelcomm, 2002: 272.

10. Lai KA, Shen WJ, Yang CY, Lin RM, Lin CJ, Jou IM. Two-stage cemenless revision THR after infection. 5 recurrences in 40 cases followed 2.5-7 years. Acta Orthop Scand 1996:67:325-8.

11. Leunig M, Chosa E, Speck M, Ganz R. A cement spacer for two-stage revision of infected implants of the hip joint. Int Orthop 1998:22:209-14.

12. Lieberman JR, Callaway GH, Salvati EA, Pellicci PM, Brause BD. Treatment of the infected total hip arthroplasty with a two-stage reimplantation protocol. Clin Orthop 1994:301:205-12.

13. Masterson EL, Masri BA, Duncan CP. Treatment of infection at the site of total hip replacement. J Bone Jt Surg 1997:79-A:1740-9.

14. McDonald DJ, Fitzgerald RH, Ilstrup DM. Two-stage revision of a total hip arthroplasty because of infection. J Bone Jt Surg 1989:71-A:828-34.

15. McElwaine JP,Colville J. Excision arthroplasty for infected total hip replacements. J Bone Jt Surg 1984:66-B:168-71.

16. Schroder J, Saris D, Besselaar PP, Marti RK. Comparison of the results of the Girdlestone pseudoarthrosis with reimplantation of a total hip replacement. Int Orthop 1998:22:215-8.

17. Šponer P, Karpaš K, Zitko D. Naše zkušenosti s odstraněním infikované aloplastiky kyčelního kloubu. Acta Chir Orthop Traum Čech 2000:67:28-32. 
18. Tsukayama D, Estrada R,Gustilo R. Infection after total hip arthroplasty. A study of the treatment of one hundred and six infections. J Bone Jt Surg 1996: 78-A:512-23.

Submitted February 2003.

Accepted June 2003.

Doc. MUDr. Karel Karpaš, CSc.,

Charles University in Prague,

Faculty of Medicine in Hradec Králové,

Department of Orthopaedic Surgery, 50005 Hradec Králové,

Czech Republic.

e-mail:dasova@centrum.cz 